Article

\title{
Evaluating the Impact of Climate Change on Paddy Water Balance Using APEX-Paddy Model
}

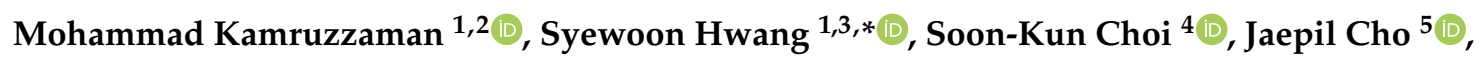

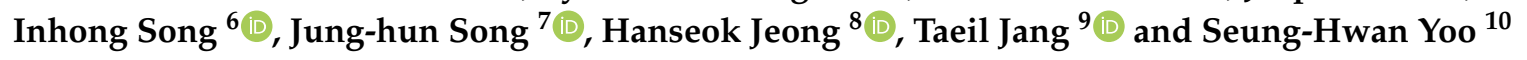

1 Department of Agricultural Engineering, Institute of Agriculture and Life Science, Gyeongsang National University, Jinju-daero 501, Jinju, Gyeongnam 52828, Korea; milonbrri@gmail.com

2 Bangladesh Rice Research Institute, Gazipur 1701, Bangladesh

3 Division of Agro-System Engineering, Institute of Agriculture and Life Science, Gyeongsang National University, Jinju-daero 501, Jinju, Gyeongnam 52828, Korea

4 Climate Change and Agro-Ecology Division, Department of Agricultural Environment, National Institute of Agricultural Science, Rural Development Administration, Wanju-gun, Jeonbuk 55365, Korea; soonkun@korea.kr

5 Convergence Laboratory for Watershed Management, Integrated Watershed Management Institute, Suwon-si, Gyeonggi-do 16501, Korea; jpcho89@gmail.com

6 Department of Rural Systems Engineering, Research Institute of Agriculture and Life Sciences, Seoul National University, Seoul 08826, Korea; inhongs@snu.ac.kr

7 Department of Agricultural and Biological Engineering and Tropical Research and Education Center, University of Florida, Homestead, FL 33031, USA; junghunsong@ufl.edu

8 Department of Environmental Engineering, Seoul National University of Science and Technology, Seoul 139743, Korea; hanjeong@seoultech.ac.kr

9 Department of Rural Construction Engineering, Institute of Agriculture Science \& Technology, Jeonbuk National University, Jeonju-si, Jeonbuk 54896, Korea; tjang@jbnu.ac.kr

10 Department of Rural and Bio-Systems Engineering, College of Agriculture and Life Sciences, Chonnam National University, 77 Yongbong-ro, Buk-gu, Gwangju 61186, Korea; yoosh15@chonnam.ac.kr

* Correspondence: swhwang@gnu.ac.kr; Tel.: +82-55-772-1934

Received: 20 February 2020; Accepted: 12 March 2020; Published: 18 March 2020

\begin{abstract}
This research aims to assess the impact of climate change on water balance components in irrigated paddy cultivation. The APEX-Paddy model, which is the modified version of the APEX (Agricultural Policy/Environmental eXtender) model for paddy ecosystems, was used to evaluate the paddy water balance components considering future climate scenarios. The bias-corrected future projections of climate data from 29 GCMs (General Circulation Models) were applied to the APEX-Paddy model simulation. The study area (Jeonju station) forecasts generally show increasing patterns in rainfall, maximum temperature, and minimum temperature with a rate of up to $23 \%, 27 \%$, and $45 \%$, respectively. The hydrological simulations suggest over-proportional runoff-rainfall and under-proportional percolation and deep-percolation-rainfall relationships for the modeled climate scenarios. Climate change scenarios showed that the evapotranspiration amount was estimated to decrease compared to the baseline period (1976-2005). The evaporation was likely to increase by $0.12 \%, 2.21 \%$, and $7.81 \%$ during the $2010 \mathrm{~s}, 2040 \mathrm{~s}$, and $2070 \mathrm{~s}$, respectively under Representative Concentration Pathway (RCP)8.5, due to the increase in temperature. The change in evaporation was more pronounced in RCP8 8 than the RCP4.5 scenario. The transpiration is expected to reduce by $2.30 \%$ and $12.62 \%$ by the end of the century (the 2070s) under RCP4.5 and RCP8.5, respectively, due to increased $\mathrm{CO}_{2}$ concentration. The irrigation water demand is generally expected to increase over time in the future under both climate scenarios. Compared to the baseline, the most significant change is expected to increase in the 2040s by $3.21 \%$ under RCP8.5, while the lowest increase was found by $0.36 \%$ in 2010 s under RCP4.5. The increment of irrigation does not show a significant difference; the rate of increase in the irrigation was found to be greater RCP8.5 than RCP4.5 except in the 2070s. The
\end{abstract}


findings of this study can play a significant role as the basis for evaluating the vulnerability of rice production concerning water management against climate change.

Keywords: water balance; paddy field; APEX-Paddy model; climate change; irrigation water demand

\section{Introduction}

Human activities since the industrial revolution have led to increased $\mathrm{CO}_{2}$ emissions from the atmosphere causing anthropogenic climate change. Global mean temperature increase is expected to rise up to $4{ }^{\circ} \mathrm{C}$ in the 21st century [1] and will have a dramatic impact on water resource quality and worldwide water demand. In addition to global warming, future climate factors such as precipitation, solar radiation, and wind velocity will also change. The change of climate will likely affect the hydrological cycle, such as evapotranspiration, runoff, percolation, deep percolation, and irrigation demand. Increased intensities of precipitation will lead to higher rates of surface runoff [2], while a rise in temperature will cause higher evapotranspiration and, in turn, further enhance the irrigation water demand [3]. As climate change is a global phenomenon, there are considerable regional differences in the impacts. Projections show that the future climate will vary significantly by region. Therefore, the effects of climate change on the water balance needs to be quantified from regional to local (basin) scales to cope with future challenges of water management.

Global Circulation Models (GCMs) are the best source for generating future climate change scenarios. However, most of the global climate models are typically run on coarse horizontal scales (usually 100-300 km). Therefore, the GCM outputs are characteristically incapable of assessing the climate change impact of any regional or local scale. The forecasts of climate variables need to be downscaled from the GCM resolution to obtain local climate change information at the desired scale, using either dynamical or statistical methods (IPCC, 2001) [4,5]. Dynamic downscaling of climate data is more representative of fine physical processes than statistical downscaling data, but high-priced computing resources are needed compared to statistical downscaling [6-8].

Conversely, there is always uncertainty in climate change research due to the presence of a number of climate models and scenarios. Since uncertainties usually emerge from a mixture of climate models, downscaling methods and hydrological models [9], taking into account the uncertainties associated with all of the above sources, will have a significant impact on the simulation results and hence on the modeling output [10]. One way to tackle this ambiguity is to include multiple climate models and efficiently measured emission scenarios using a statistical approach which is well accepted in the scientific community and commonly used in downscaling climate projections [11]. Hence, the outputs of a larger number of GCMs are therefore better at reflecting the systemic uncertainty in climate models [12]. The Coupled Model Intercomparison Projects (CMIPs) of the World Climate Research Program (WCRP) have made outputs of the general circulation model (GCM) accessible, phase-wise. This is designed in phases to promote changes to the climate model; however, these items have played an important role in measuring climate variability. Sperber et al. [13] have shown that the CMIP5 models are more capable of capturing certain aspects of the Asian monsoon environment. According to the results of the cited studies, the temperature would rise, and rainfall distribution would be different under climate change. Given the above evidence, predicting future changes in the hydrological cycle by using climate data from the new sets of CIMP5 GCM projections on a regional scale is of supreme importance.

In South Korea, agricultural water withdrawals account for approximately $47 \%$ of total water use in the country (Ministry of Construction and Transportation, Republic of Korea [14]. Most agricultural water use is for paddy rice irrigation. Moreover, over $80 \%$ of total paddy fields $(777,000$ ha) have been irrigated; thus, irrigation water in paddy fields is the main problem in terms of agricultural water 
management. Science climate change will change the patterns of temperature and rainfall, it will further impact directly on the water balance because of the crop water needs [15]. As the requirement for irrigation water depends on the balance between rain and evapotranspiration (ET), the demand for irrigation is highly sensitive to global climate change [16] and is very sensitive to changes in precipitation, atmospheric $\mathrm{CO}_{2}$ concentration, and temperature [17]. Jee et al. [18] evaluated the effect of global climate change on agricultural water requirements in South Korea's Nakdong River basin under scenarios A1B, A2, and B1 from the Special Emission Scenarios Study (SRES). They found that demand for agricultural water increased at nearly every period, with the exception of 2011-2040, due to climate change. Chung et al. [19] found that, under a climate change scenario, the use of rice-consuming water throughout the growing period was expected to increase considerably within the 2050s and 2080s. After transplantation in the study areas, it could increase from the baseline value of $534 \mathrm{~mm}$ by 2.2, 5.1, and 7.2\% over the 2020s, 2050s, and 2080s, respectively. It is therefore necessary to understand the impact of climate change on the change of available rainfall, evapotranspiration, and irrigation water requirements, simultaneously, during South Korean paddy cultivation.

The impacts of climate change on the water balance cannot be measured precisely because of the complicated interaction mechanisms between climate influences, the water cycle and the processes of vegetation [20]. In this case, hydrological modeling is seen as an important approach to understanding the powers of the hydrological cycle and exposes its mechanism for reacting to climate change [21-23]. Over the year, several mathematical models were developed to simulate water balance, and nutrients fate in flooded rice cultivation in particular, such as Chemicals, Runoff, and Erosion from Agricultural Management Systems in Paddy fields (CREAMS-PADDY) [24], Groundwater Loading Effects of Agricultural Management Systems in paddy fields (GLEAMS-PADDY) [25], and the Hydrological Simulation Program-FORTRAN model in Paddy fields (HSPF-Paddy) [26] was developed for field scale simulation. However, these models are not used for the impact of climate change, considering the increasing $\mathrm{CO}_{2}$ concentration, to simulate water balance in paddy cultivation. In addition to forcing climate, increasing concentrations of atmospheric $\mathrm{CO}_{2}$ influence the water balance through changes in transpiration, plant structure, and distribution. Leipprand and Gerten [27] quantified $\mathrm{CO}_{2}$ effects on evapotranspiration, soil moisture and runoff under conditions of possible global and regional natural vegetation using a climate-forced biosphere model (1961-1990) and found that $\mathrm{CO}_{2}$ effects add substantial variability to hydrological processes at both levels. Therefore, it is essential to consider increasing $\mathrm{CO}_{2}$ concentration to estimate climate change effects on water balance components in irrigated paddy environment.

Recently, the Rural Development Academy (RDA), South Korea, along with Texas A\&M University, revised the original Agricultural Policy/Environmental eXtender (APEX) model to enable the incorporation of paddy management practices into water balance component simulation, taking into consideration $\mathrm{CO}_{2}$ concentration. Choi et al. [28] have applied the APEX-Paddy model to estimate crop yield and evapotranspiration in paddy cultivation using the future climate provided by Korean Metrological Administration (KMA) provided climate change scenarios and found that evapotranspiration will be reduced in the future. Conversely, APEX-Paddy has also shown to simulate increasing trends in future evapotranspiration rates by using climate data from the downscaled 9 GCMs in another study by Choi et al. [29]. This inconsistency may have been due to the lack of realistic climate information. Nevertheless, the use of the APEX-Paddy model, which is the prime motivation for this research, has not yet been used in a comprehensive study of the impact of climate change on paddy water balance.

Therefore, taking into account the above facts, the overall objective of this research is to quantify the impacts of future climate change on the water balance of paddy cultivation. We used the APEX-Paddy model for the Ikasn region of South Korea in combination with downscaled and bias-corrected CMIP5 GCM outputs of various climatic parameters. This study will help local water managers, farmers, researchers and policy makers understand the potential impacts of climate change and establish adaptation strategies for local agricultural water management. 


\section{Materials and Methods}

\subsection{Study Area and Experiment Field Management}

The experiment was conducted at the Seoul National University research field $\left(35.9016^{\circ} \mathrm{N}\right.$, $127.0331^{\circ} \mathrm{E}$ ), located near Ikasn city of the Jeonbuk province in South Korea, as shown in Figure 1. The predominant soils at the Iksan experimental site are Jeonbug series. The series Jeonbug is a poorly drained silty loam soil series built on the fluvio-marine plain. The upper layer of the soil's physical properties $(\sim 20 \mathrm{~cm})$ contains $11.1 \%$ sand, $71.1 \%$ silt, and $17.8 \%$ clay. The daily metrological records of this study were retrieved from the Jeonju metrological station. Total rainfall in the area during the cropping season (May to October) ranged from $707.1 \mathrm{~mm}$ to $1860 \mathrm{~mm}$ in 1976-2005, and the average annual rainfall of 30 years was around $1300 \mathrm{~mm}$, whereas the average maximum and minimum temperatures were around $27^{\circ} \mathrm{C}$ and $17^{\circ} \mathrm{C}$, respectively. Seasonally, the monsoon, a rainy season in Korea between July and August, is highly influenced by precipitation at the study sites. Approximately $52 \%$ of the annual rainfall occurs in this region during this time, and part of the increasing rice season includes the monsoon period.

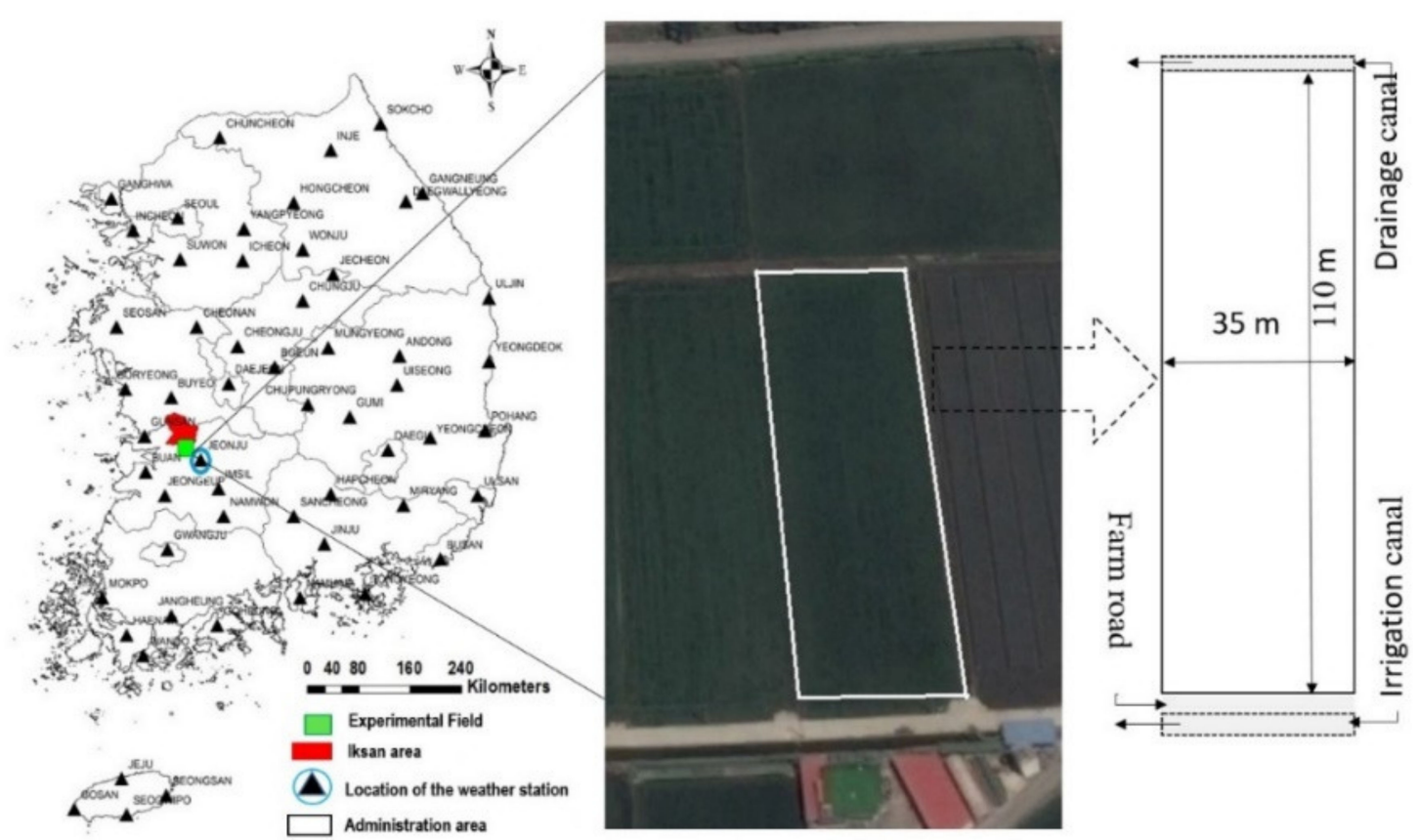

Figure 1. Geographical location of the study area. Schematic map of experimental plots located near Ikasn city of the Jeonbuk province, South Korea. Map showing the location of Jeonju weather station.

A 'Saenuri' Japonica rice variety is seeded and grown in nursery beds for 25-30 days and then transplanted after 1.5-2 leaves appear. Transplantation is the most common rice cultivation process, and is carried out in paddy fields between mid-May and mid-June. The land preparation (i.e., puddling) and transplantation process occurs between May and August, during which water demand reaches its peak. Normally the rice is harvested in October. The rice is usually harvested in October. Paddy fields are adequately irrigated in paddy cultivation to ensure ponding of the soil. Korea's paddy fields are surrounded by earth berm of around $10-30 \mathrm{~cm}$ in height and filled with water 3-10 cm in depth for most of the growing season to control weeds and to maximize rice yield [30]. Artificial surface drainage of 1 to 2 weeks in the midseason is a common practice in Korea to improve air supply to the rice root zone and increase the number of tillers used to lodge robust rice stalk tolerance [31]. Apart from mid-summer drainage, irrigation water is applied as a continuous flooding condition between most tillering stages and initiation stages of panicles. 
The experimental paddy fields were $35 \mathrm{~m}$ wide, and $110 \mathrm{~m}$ long in size, and paddy water level, outflow and water quality were investigated during the growing season of 2013 to 2015. The standing water level reached a depth of max. $7 \mathrm{~cm}$. At the time of transplantation, however, the depth was set at $4 \mathrm{~cm}$. Irrigation water was artificially applied when for a specific period the water level reached below the ponding depth assigned. Specified management activities dates, including transplantation, fertilizer and water management are provided in Table 1. A weir was also installed at the paddy field drainage outlet to measure the drainage water amount. The outlet weir was also used to control the ponding depth inside the paddy field. An ultrasonic water level gauge was used to measure paddy ponding depth. The water samples of paddy fields were collected at regular intervals of 15 days. However, rainfall-runoff samples were collected when a major storm occurred. Continuous monitoring of irrigation and surface discharge water at the paddy field was performed for model calibration and validation at the Iksan site from June to September 2013, and from May to September 2014 and 2015, respectively.

Table 1. Farming activities at the experimental paddy fields.

\begin{tabular}{cccc}
\hline Operation & $\mathbf{2 0 1 3}$ & $\mathbf{2 0 1 4}$ & $\mathbf{2 0 1 5}$ \\
\hline Start irrigation & 8 June & $20 \mathrm{May}$ & 17 May \\
Fertilizer application & $11 \mathrm{June}$ & $25 \mathrm{May}$ & $20 \mathrm{May}$ \\
Tillage operation & $(\mathrm{N}=126 \mathrm{~kg}, \mathrm{P}=57 \mathrm{~kg})$ & $(\mathrm{N}=126 \mathrm{~kg}, \mathrm{P}=57 \mathrm{~kg})$ & $(\mathrm{N}=126 \mathrm{~kg}, \mathrm{P}=57 \mathrm{~kg})$ \\
Transplanting & $12 \mathrm{June}$ & $25 \mathrm{May}$ & $20 \mathrm{May}$ \\
Irrigation ponding & $13 \mathrm{June}$ & $29 \mathrm{May}$ & $28 \mathrm{May}$ \\
Mid-term dry period & $14 \mathrm{June}$ & $30 \mathrm{May}$ & $28 \mathrm{May}$ \\
Harvesting & 7-21 July & $11-19 \mathrm{July}$ & $26 \mathrm{June}-30 \mathrm{July}$ \\
\hline
\end{tabular}

\subsection{Model Selection and Setup}

APEX is a watershed model for simulating the effect of agricultural management on water quality, nutrient cycling and carbon dynamics in soil-plant systems running on a day-to-day basis [32,33]. APEX defines land areas with unique soil property, vegetation or land use, and the land slope as subareas. Thus, a watershed is delineated into a series of sub-areas linked hydrologically by a stream network.

The APEX-Paddy model was developed because the APEX model is not designed to simulate ponded rice paddy field conditions. The APEX-Paddy model is a revised version of the APEX model which is physically based on field scale to more accurately simulate water balance components such as surface discharge, irrigation, percolation, deep percolation, etc., from paddy fields under ponded conditions [34]. In this study, the APEX-Paddy model was applied to estimate the water balance components from rice paddy fields.

Soil characteristics are essential factors when modeling discharge from a basin. In this study, the hydrologic soil group 'B' was selected since paddy fields were terraced. In APEX, a user may either create a new weather station or use one of the default stations defined by the program [35]. As APEX works on a daily time step, Jeonju weather station data were used to prepare a Daily Weather File (.DLY). Six parameters were used in the weather data file: precipitation, maximum and minimum temperature, solar radiation, relative humidity and wind speed for the period 1976-2015, which were used for the calibration and validation of the model.

APEX provides five different options for estimating potential evaporation such as Hargreaves, Penman, Priestley-Taylor, Penman-Monteith, and Baier-Robertson. Penman and Penman-Monteith are the most data intensive methods requiring solar radiation, air temperature, wind speed and relative humidity as inputs. A few GCMs, however, are limited to providing certain parameters, such as solar radiation, wind speed and relative humidity. In this study, therefore, the Hargreaves and Samani equation [36] were used for future estimation of possible evapotranspiration (PET). Hargreaves is a temperature-based model and uses temperature and extraterrestrial radiation to estimate daily PET. It is obvious that the Hargreaves method provides the best estimate of PET when data are not available 
on relative humidity, and wind speed [37]. When a sub-area is configured to simulate the management of paddy rice, APEX-Paddy moves from the Soil Conservation Service Curve Number SCS-CN [38] system to a weir discharge mechanism to regulate the paddy water balance. APEX-Paddy switches back to default sub-area modules to model upland non-ponding land processes, such as the SCS-CN system for runoff estimation, during off-seasons or when paddy field management does not introduce water ponding.

The $\mathrm{CO}_{2}$ data was collected from the United Nations Food and Agriculture Organization (FAO) input database built model known as the FAO-AquaCrop 5.0 model, previously used by Choi et al. [28]. The carbon dioxide concentration input of the model is represented by the RCP scenario of the 5th Intergovernmental Panel on Climate Change (IPCC) report. Average values of $\mathrm{CO}_{2}$ concentration for each period applied to the APEX-Paddy model are shown in Table 2.

Table 2. The $\mathrm{CO}_{2}$ data was obtained from the input database of the FAO-AquaCrop 5.0 model.

\begin{tabular}{ccccc}
\hline Period & Historical (1976-2005) (ppm) & 2010 (ppm) & 2040s (ppm) & 2070s (ppm) \\
Scenario & 363.09 & 424.88 & 497.47 & 532.43 \\
RCP4.5 & 363.09 & 435.65 & 578.07 & 807.17 \\
RCP8.5 & & & \\
\hline
\end{tabular}

\subsection{Model Calibration and Validation}

As calibrating a model with a greater number of parameters is a difficult task, a sensitivity analysis was done to reduce the calibration effort. The parameter selection for sensitivity analysis was made based on the characteristics of the study area as well as the literature review.

For model calibration and sensitivity analysis the APEX-auto Calibration and UncerTainty Estimator (APEX-CUTE) programs (4.1 edition, Texas A\&M AgriLife Research, Temple, TX, USA, https:/epicapex.tamu.edu/apex/) were used. APEX-CUTE offers a sensitivity analysis using the Morris method [39]. The sensitivity analysis was conducted to determine the rate of change in model outputs based on the degree of change to the value of a sensitive parameter. This step is essential to identifying and defining parameters that influenced the model outputs most. APEX-CUTE uses a Dynamically Dimensioned Search (DDS) algorithm for model calibration [40]. The DDS algorithm drives the model by sequentially applying candidate values as input data until the objective function maximum value is derived, and then calculating the model's actual statistics. To generate another candidate value that is added to the model, random changes are made to the optimized value. APEX-CUTE is programmed to replicate the above cycle as many times as the predetermined objective function is evaluated. The calibration process involved editing parameter values, running the model, and assessing the results. Continued changes in parameter values depended on the over or under-prediction of the model results. If the final fit is deemed adequate, the model is considered calibrated.

The model was evaluated based on the statistical relationship between the simulated and observed surface discharge outputs. It is recommended that both graphical techniques and quantitative statistics be used in model evaluation [41]. Three different evaluation statistics were used to quantify this study, including coefficient of determination $\left(\mathrm{R}^{2}\right)$, Nash-Sutcliffe Efficiency (NSE), and Percent Bias (PBIAS). One of the most commonly used criteria in model performance is the $\mathrm{R}^{2}$ correlation coefficient (Equation (1)), which is used to determine the goodness of fit [41]. Values for $R^{2}$ (bound by 0 and 1 ) that are closer to 1 indicate a better fit, with an amount of 1 indicating a perfect match for comparing predicted values to observed data. The NSE suggests that field data means should be used for more accurate results, rather than the simulated values, where the derived value ranges from 0 to 1.0. The similar the values and field data that are represented, the closer the derived value is to 1.0 [42]. The NSE calculation was carried out using Equation (2). PBIAS measures key performance trends by estimating the number of residuals, the difference between real and predicted data points by standardizing the amount of data observed [41]. The optimal value for PBIAS is 0 , with low-magnitude values 
showing precise simulation of the model [41]. Positive and negative values, respectively, represent under-estimation of model and bias in overestimation. Calculation of PBIAS was performed using Equation (3).

$$
\begin{gathered}
R^{2}=\left[\frac{\sum(x-\bar{x})(y-\bar{y})}{\sqrt{ } \sum(x-\bar{x})^{2} \sum(y-\bar{y})^{2}}\right]^{2} \\
N S E=1-\left[\frac{\sum(y-x)^{2}}{\sum(y-\bar{y})^{2}}\right] \\
\text { PBIAS }=\left[\frac{\sum(y-x)}{\sum(\mathrm{y})}\right] \times 100
\end{gathered}
$$

In the equation, $\mathrm{x}$ and $\mathrm{y}$ are the predicted and observed values, $\bar{x}$ and $\bar{y}$ are the means of $\mathrm{x}^{\prime} \mathrm{s}$ and $y^{\prime}$ s.

Moriasi et al. [41] have proposed evaluation criteria focused on the watershed model's output importance. If daily, weekly, or annual $\mathrm{R}^{2}>0.60$, NSE $>0.50$, and PBIAS $\pm 15 \%$ for surface discharge, they suggest that model performance can be considered "satisfactory." In this analysis the model simulation outcome was evaluated on the basis of these criteria. The process of calibration was described in detail in the previous study [43].

\subsection{Water Balance Model of Irrigated Paddy Field}

APEX-Paddy provides a set of new subroutines to simulate water ponding, discharge control, and paddy management [34]. Figure 2 shows the factors affecting water balance in the paddy fields. Irrigation should supply the deficiency of water that paddy growth needs. The rise of the capillary from groundwater is overlooked in this study. Further, given the practices of rice cultivation followed in South Korea, the bunds are generally restricted before puddling which does not allow for the puddled layer to spread below the bund. In addition, field topography is almost flat so cross flow (lateral flow/loss of seepage) through the bunds is not considered.

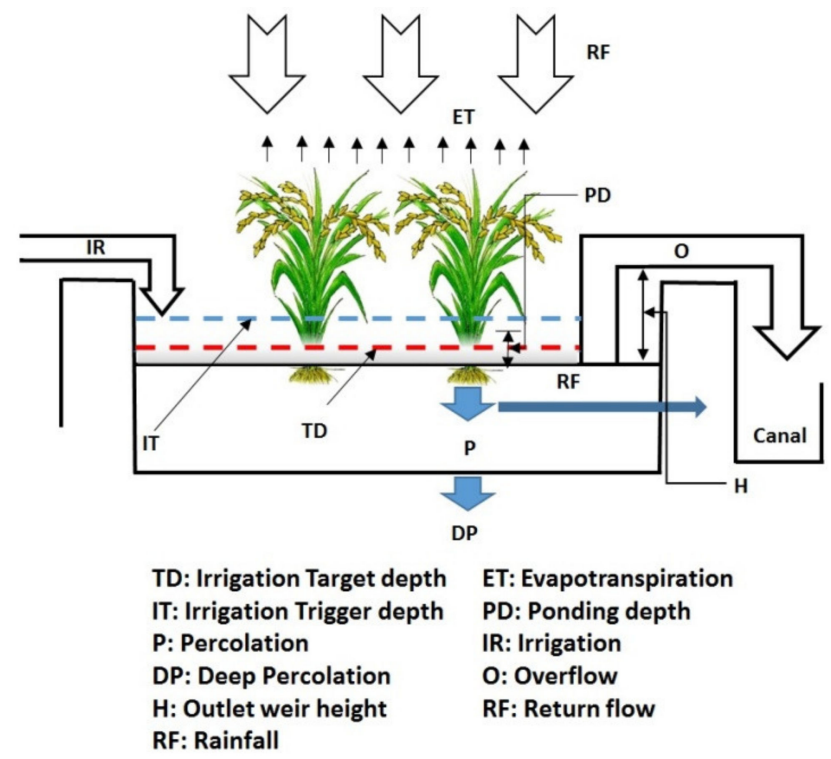

Figure 2. Paddy water budget in Agricultural Policy/Environmental eXtender (APEX)-Paddy model.

The time allowed for this study was $24 \mathrm{~h}$. At the end of the day $(24 \mathrm{~h})$, paddy field ponding depth was the sum of the previous day's paddy field water level and precipitation minus daily evapotranspiration and infiltration (percolation and Deep percolation). If paddy field water levels were lower than the irrigation trigger depth (IT), the model was constructed to irrigate by the difference 
between the irrigation target depth (TD) and the current paddy field water level as shown in Figure 2. If the paddy field level was higher than the height of the water, then a drainage or surface discharge (O) occurred.

The APEX-Paddy model calculates the daily water budget in the following equations:

$$
\begin{gathered}
P D_{t}=P D_{t-1}+R F_{t} \\
I R_{t}=T D-P D_{t}, P D_{t}^{\prime}=T D-E T_{t}-P_{t}, \text { if } P D_{t} \leq I \mathrm{~T} \\
P D_{t}^{\prime}=P D_{t}-O_{t}-E T_{t}-P_{t}, \text { if } P D_{t}>H \\
O_{t}=\sum_{h=1}^{24}\left(1.838 b\left(\frac{P D_{t, h}-H}{1000}\right)^{3 / 2}\right) \\
P D_{t, h}=P D_{t}-\sum_{i}^{h} O \\
P D_{t}^{\prime}=P D_{t}-E T_{t}-P_{t}, \text { if } I T<P D_{t} \leq H
\end{gathered}
$$

where $t$ is the simulation time (day), $P D$ is the ponding depth $(\mathrm{mm}), P D^{\prime}$ is the ponding depth after surface discharge, evapotranspiration and runoff loss $(\mathrm{mm}), R F$ is the rainfall $(\mathrm{mm}), I R$ is the irrigation $(\mathrm{mm}), T D$ is the irrigation target depth $(\mathrm{mm}), E T$ is the evapotranspiration $(\mathrm{mm}), P$ is percolation $(\mathrm{mm})$, $I T=$ irrigation trigger depth $(\mathrm{mm}), O$ is the overflow or surface discharge $(\mathrm{mm}), H$ is the outlet weir height, and $b$ is outlet weir width $(\mathrm{m})$.

\subsection{Future Climate Change Scenarios}

A Representative Concentration Pathway (RCP) is a trajectory adopted by the IPCC to concentrate greenhouse gas (not emissions). In 2014 the IPCC Fifth Assessment Report (AR5) used four methods for climate modeling and analysis. The strategies represent different climate scenarios which are all considered feasible, depending on the volume of greenhouse gases (GHG) emitted over the coming years. The RCPs, originally RCP2.6, RCP4.5, RCP6, and RCP8.5, are numbered to the year 2100 after a possible range of radiative forcing values. RCP4.5 is a long-term, global greenhouse gas emission scenario, short-lived process, and land-use-land cover stabilizing radiative forcing at 4.5 $\mathrm{W} / \mathrm{m}^{2}$ (approximately 650 ppm $\mathrm{CO}_{2}$-equivalent) in the year 2100 without ever reaching that value, while the RCP8.5 combines assumptions approximately high population and relatively slow income growth with modest rates of technological change and energy intensity improvements, leading in the long term to high energy demand and GHG emissions in absence of climate change policies [1]. In this case, the greenhouse gas emissions and concentrations increase considerably over time, resulting in a radiative forcing of $8.5 \mathrm{~W} / \mathrm{m}^{2}$ (greater than $1370 \mathrm{ppm} \mathrm{CO}$-equivalent) at the end of the century [1].

The CMIP5 offers a standard set of GCM model simulations based on common procedures [44]. The climate change scenarios were acquired from outputs of 29 CMIP5 GCMs under two 4.5 and 8.5 RCP scenarios, which were used in this study to determine the impact of climate change on water balance in irrigated paddy cultivation. Table 3 provides summary information on the GCMs used in this study. The results of the GCM vary greatly in the spatial resolution and include inherent biases that need to be adjusted before the climate change impact assessment procedure. In this study, daily data were downscaled from 1976 to 2100 and bias-corrected against the observation data from Jeonju weather station by using a simple quantile mapping (SQM) method [45]. The SQM technique performs independent improvements by observation points and climate variables through an empirical quantile mapping approach. The SQM followed the three-step process: (1) extracting the GCM grid data corresponding to the target station, (2) assessing the biases of the retrospective simulations and (3) correcting the potential predictions by bias. In other words, every GCM has extracted a single grid that covers the target station. The biases of retrospective simulation outputs for the selected grid were calculated as opposed to observations. The discrepancies between the simulated functions of 
cumulative distributions (CDFs) and that observed for the retrospective duration were quantified and then extended for a given percentile to future simulations (Equation (8)):

$$
\mathrm{x}_{p}^{\prime}(t)=\mathrm{x}_{p}(t)+\mathrm{F}_{\mathrm{obs}}^{-1}\left(\mathrm{~F}_{p \cdot \operatorname{sim}}\left(\mathrm{x}_{\mathrm{p}}(t)\right)\right)-\mathrm{F}_{\mathrm{r} \cdot \operatorname{sim}}^{-1}\left(\mathrm{~F}_{p \cdot \operatorname{sim}}\left(\mathrm{x}_{p}(t)\right)\right)
$$

where $x_{p}^{\prime}(t)$ and $x_{p}(t)$ denote the bias-corrected and raw future projections on day $t$, and $F(\theta)$ and $F^{-1}(\theta)$ are a CDF of the daily data $\theta$ and its inverse, respectively. The subscripts p.sim, r.sim, and obs indicate the future projection, retrospective simulation, and observed daily data, respectively.

Table 3. Summary of Coupled Model Intercomparison Projects (CMIP) 5 climate models used in this study.

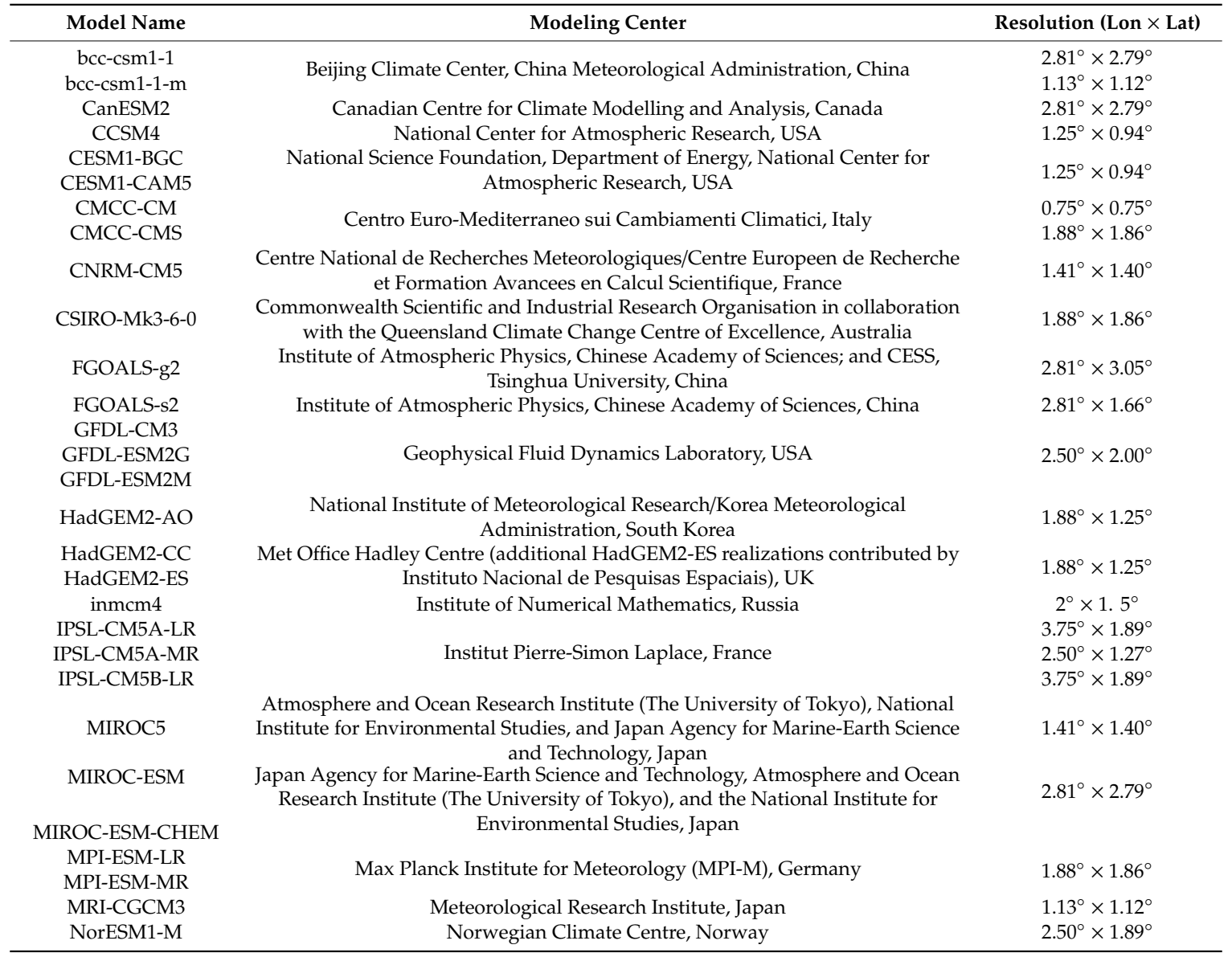

Using the non-parametric empirical equation, the sum of daily observation and raw GCMs data are temporary measurements. According to Gudmundsson et al. [46], as compared with the parametric approach, the nonparametric approaches showed better success in minimizing systemic bias. This is because non-parametric approaches use the real distribution of observed and simulated results, without requiring a distribution function of probability.

Climatological projections are determined by the estimated 30 year (climatological) climate change over the 2010s (beginning of the century), 2040s (mid-century), and 2070s (end-of-century) as opposed to the 1976-2005 baseline.

\subsection{Changes Rates}

The rates of changes were calculated by considering four (04) different periods. The first period is the baseline period (Historical, 1976-2005). The three other periods are the projected periods (2010-2039 
(2010s), 2040-2069 (2040s), and 2070-2099 (2040s)). For each period, the mean was calculated and then the rate of changes was calculated using Equation (9).

$$
\text { Change rate }=\frac{X p-X o}{X o} \times 100
$$

where $X p$ is the mean value over the considered projected period, and $X o$ is the mean value over the historical period.

\section{Results and Discussion}

\subsection{Model Calibration and Validation}

The APEX-Paddy model was calibrated using the daily surface discharge data obtained from the paddy fields with conventional management during the cropping period of 2013 and 2014. The statistical measures of the $\mathrm{R}^{2}$, NSE, and PBIAS downscale dynamical for the quantitative test of the model performance. The results of model performance are displayed in Table 4. The hydrology sub-module performed well with the statistics of $0.78,0.65$, and $5.41 \%$ for $\mathrm{R}^{2}$, NSE, and PBIAS, respectively, for the calibration period. The hydrological yield simulation model proved to be strong enough for the long-term application according to Moriasi et al.'s [41] decision criteria. The detailed calibrated results are found in the previous study [43].

Table 4. Performance statistics for the calibrated APEX-Paddy model, including the coefficient of determination $\left(\mathrm{R}^{2}\right)$, Nash Sutcliffe model efficiency equation (NSE), and Percent Bias (PBIAS).

\begin{tabular}{cccccc}
\hline \multirow{2}{*}{ Variable } & \multirow{2}{*}{ Statistical Index } & \multicolumn{3}{c}{ Calibration Period } & Validation Period \\
\cline { 3 - 6 } & & $\mathbf{2 0 1 3}$ & $\mathbf{2 0 1 4}$ & Entire Period & $\mathbf{2 0 1 5}$ \\
\hline \multirow{2}{*}{$\mathbf{Q}$} & $\mathrm{R}^{2}$ & 0.81 & 0.71 & 0.78 & 0.67 \\
& $\mathrm{NSE}$ & 0.87 & 0.40 & 0.65 & 0.74 \\
& $\mathrm{PBIAS}(\%)$ & -8.04 & 15 & 5.41 & $6.12 \%$ \\
\hline
\end{tabular}

The calibrated APEX-Paddy model was validated using the daily surface discharge data obtained during the cropping season of 2015 from the paddy fields under traditional management. The $\mathrm{R}^{2}$, NSE, and PBIAS statistical tests were used to quantitatively assess the model results. Figure 3 displays the yield of the simulated surface discharge against the values observed for the validation periods.

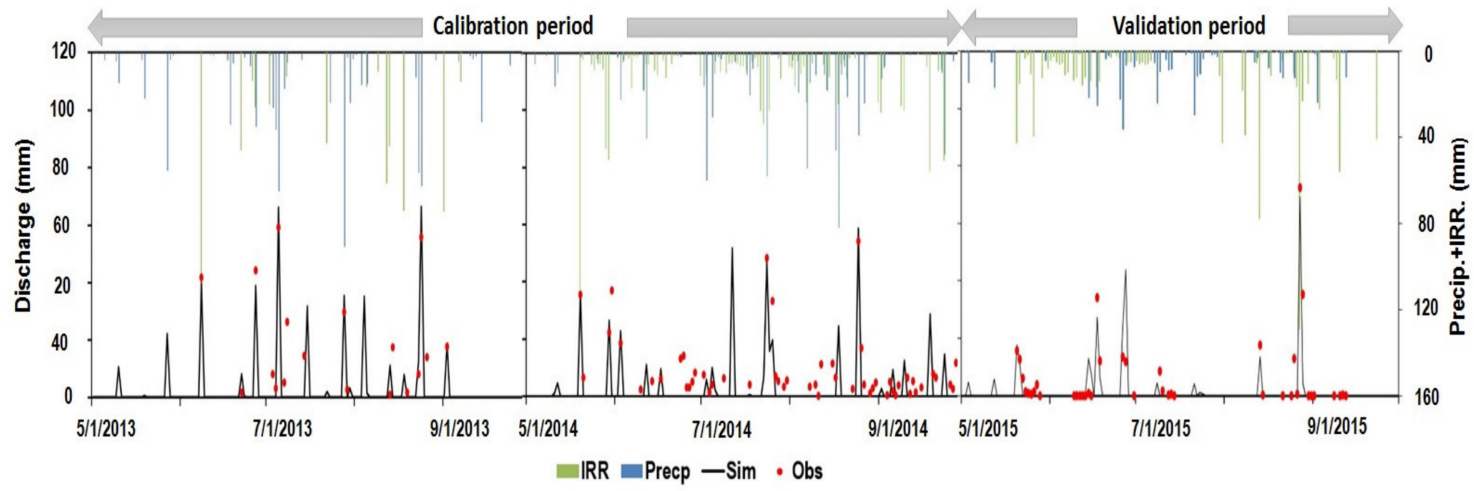

Figure 3. Predicted paddy field discharges are calibrated for the growing season in 2013-2014 and then validated for the year 2015 at the Iksan experiment site.

The hydrology sub-module performed excellently with the statistics of $0.67,0.74$, and $6.12 \%$ for $\mathrm{R}^{2}$, NSE, and PBIAS, respectively as shown in Figure 3 . The predicted values follow the performance evaluation requirements suggested by Moriasi et al. [41] for the model. 


\subsection{Evaluations for Retrospective Simulations of GCMs}

Comparison with observed data, including precipitation, maximum and minimum temperature, was used to assess the reproducibility of outputs from 29 CMIP5 GCMs for the period from 1976 to 2005. The statistical characteristics of each GCM model were compared with an observed median to analyze each model's output before (raw) and after bias-correction, and the findings are reported in Figure 4. The bias-corrected GCM results tended to accurately capture the observed trends of annual precipitation, mean maximum, and minimum temperature, whereas the raw GCM outputs showed significant biases from the observed values.
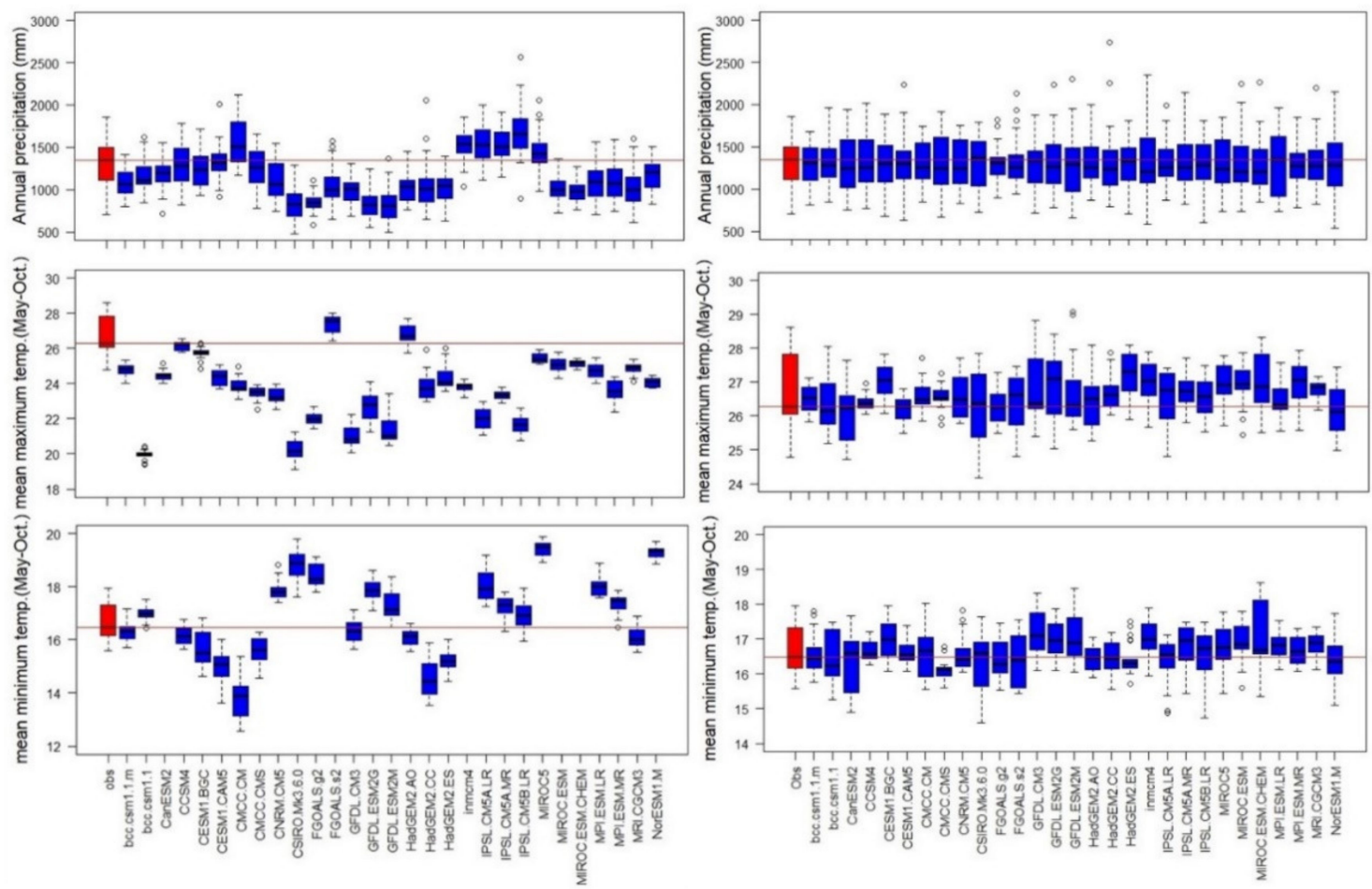

Figure 4. Comparison of raw (left) and bias-corrected (right) reproducibility with observed data for Jeonju stations in terms of the annual precipitation, mean maximum temp. (June-September), and mean minimum temp. (June-September).

In particular, the annual precipitation and maximum temperature of the raw GCM outputs tended to be underestimated systematically, while minimum temperature tended to be overestimated. Most of the errors were removed after bias-correction; only fractions of errors that originated from the temporal pattern of rainfall and temperature have remained.

\subsection{Test of the Automatic Irrigation System}

The APEX-Paddy model can also simulate irrigation amounts for different management practices using an automatic irrigation option. For automated irrigation simulation, the target and minimum ponding depth need to be provided through the APEX-Paddy management file.

The applicability was during the 2013 and 2014 cropping season of an automated irrigation method used to simulate irrigation amounts for traditional management practices. The comparison of observed and model-simulated annual irrigation amount is shown in Figure 5. The overall performance of the auto irrigation simulation was reasonably good in estimating the irrigation amount. Results show that the PBIAS value $( \pm)$ in $2013(8.42 \%)$ was less than in $2014(13.3 \%)$, of which average would fit into a satisfactory level. Therefore, the conventional management practice with 2013 can be used for long-time simulations under climate change scenarios. 


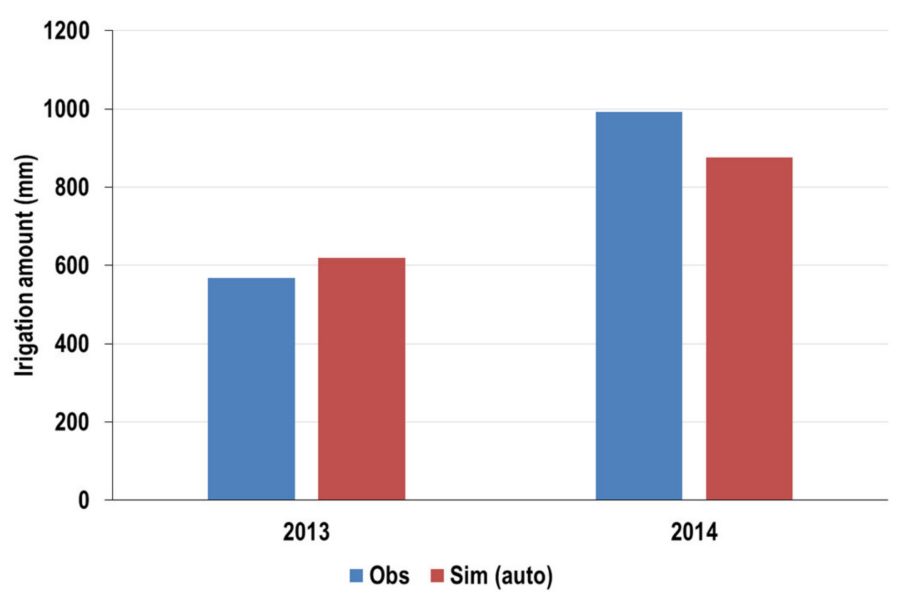

Figure 5. Comparison of observed and simuated irrigation amount for 2013 and 2014 applying the auto-irrigation option of APEX-Paddy model.

\subsection{GCM Skills in Reproducing Surface Discharge}

Reproducibility of evapotranspiration, surface discharge, and irrigation was evaluated through model outputs calculated from bias-corrected GCMs projected climate data, which were compared with the observed model values calculated from the weather station data from 1976 to 2005 . The average evapotranspiration, surface discharge and irrigation from 29 GCMs for the same period were considered as historical outputs over 30 years. Overall, the statistical index (PBIAS) of the model showed reasonable consistency between the simulations from bias-corrected GCMs projected climate data and observed station data.

Table 5 presents the simulated results of evapotranspiration, surface discharge, and irrigation in the comparison between the GCMs outputs and the weather station data. It was found that the simulation of evapotranspiration and surface discharge from GCMs outputs tended to be lower than the observed one, while irrigation presented a higher value. Overall, PBIAS statistics were reasonably small enough to fit into the satisfactory level, as suggested by Moriasi et al. [41].

Table 5. Comparison of surface discharge calculated from observed climate data and bias-corrected General Circulation Models (GCMs) data for 1976-2005. Values in parentheses refer to the standard deviation of the results over the GCMs.

\begin{tabular}{cccc}
\hline Water Balance Components & Evapotranspiration & Surface Discharge & Irrigation \\
\hline MME of GCMs & $517.60( \pm 4.49)$ & $375.44( \pm 18.1)$ & $633.57( \pm 30.08)$ \\
Observed & 533.84 & 382.25 & 613.25 \\
PBIAS $(\%)$ & 3.04 & 1.78 & 3.31 \\
\hline
\end{tabular}

\subsection{Future Change in Precipitation, Maximum and Minimum Temperature}

Total precipitation, and maximum and minimum temperature of the cropping period (June to September) over the GCMs were evaluated in the 2010s, 2040s, and 2070s, compared to the baseline period (1976-2005) under the RCP4.5 and RCP8.5 scenarios (Figure 6). The projected percentage change in precipitation, and maximum and minimum temperature tended to increase in the future over the experimental areas, as shown in Table 6. 


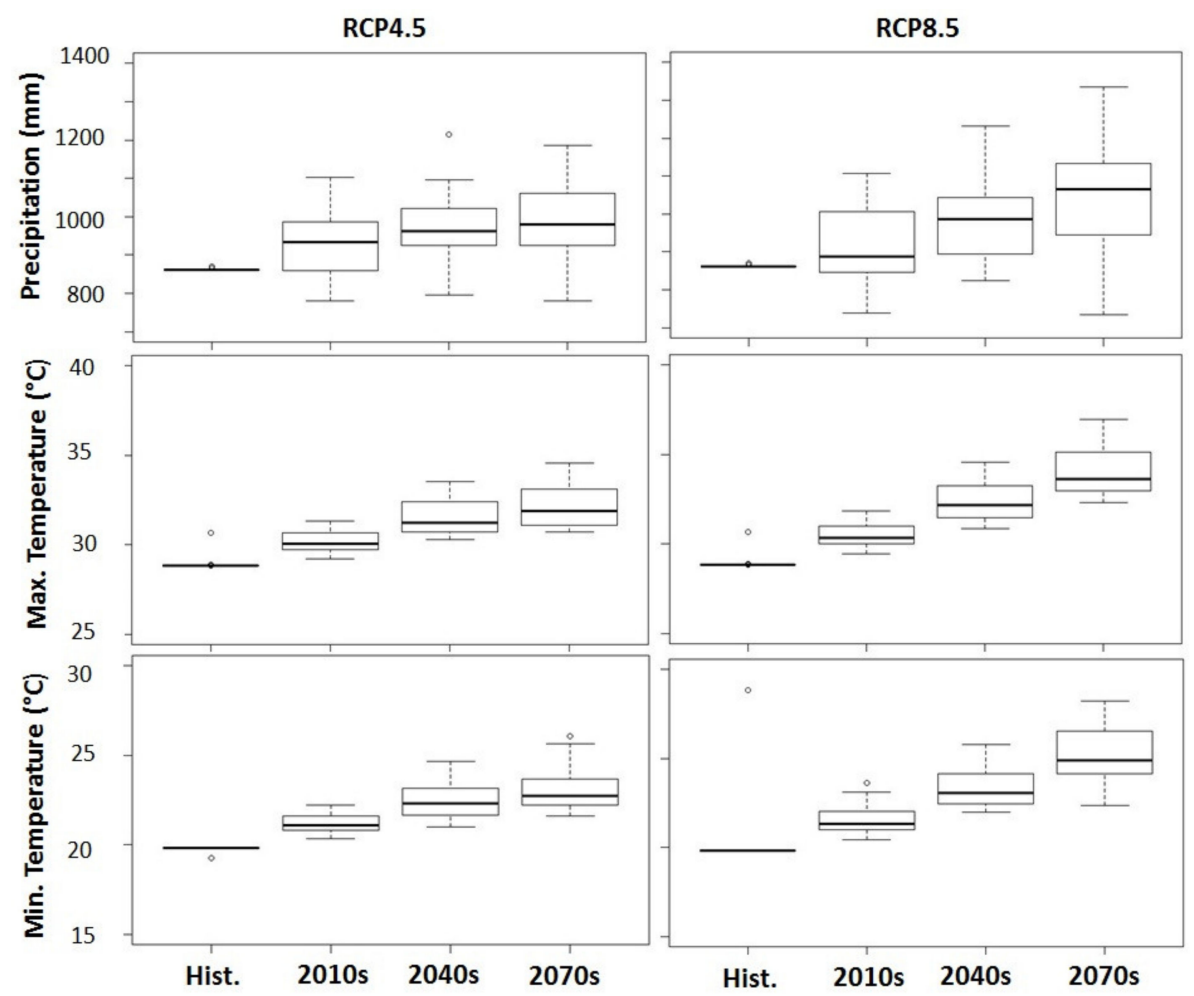

Figure 6. Percentage (\%) change of total precipitation, mean maximum temperature and minimum temperature during the cropping period (June-September) in Jeonju metrological station for the 2010s (2nd column), 2040s (3rd column), 2070s (4rd column) considering RCP4.5 (left side) and (2) RCP 8.5 (right side) scenarios relative to the historical period (1st column) considered as baseline (1976-2005).

Table 6. The multimodal ensemble (MME) means of historical agroclimatic and water balance parameters, and climate change period and percent change in comparison to the historical period in parenthesis.

\begin{tabular}{|c|c|c|c|c|c|c|c|c|}
\hline \multirow{2}{*}{ Parameters } & \multicolumn{4}{|c|}{ RCP4.5 } & \multicolumn{4}{|c|}{ RCP8.5 } \\
\hline & Historical & $2010 s$ & 2040s & $2070 s$ & Historical & 2010s & 2040s & 2070s \\
\hline Precipitation (mm) & 861.46 & $\begin{array}{l}934.56 \\
(8.49)\end{array}$ & $\begin{array}{l}968.69 \\
(12.44)\end{array}$ & $\begin{array}{l}986.12 \\
(14.47)\end{array}$ & 861.46 & $\begin{array}{r}916.42 \\
(6.38)\end{array}$ & $\begin{array}{l}981.91 \\
(13.98)\end{array}$ & $\begin{array}{l}1059.58 \\
(23.00)\end{array}$ \\
\hline $\operatorname{Tmax}\left({ }^{\circ} \mathrm{C}\right)$ & 28.89 & $\begin{array}{c}33.31 \\
(15.32)\end{array}$ & $\begin{array}{l}31.53 \\
(9.15)\end{array}$ & $\begin{array}{c}32.12 \\
(11.22)\end{array}$ & 28.89 & $\begin{array}{c}36.61 \\
(26.73)\end{array}$ & $\begin{array}{c}32.34 \\
(11.95) \\
\end{array}$ & $\begin{array}{c}34.16 \\
(18.24)\end{array}$ \\
\hline $\operatorname{Tmin}\left({ }^{\circ} \mathrm{C}\right)$ & 19.81 & $\begin{array}{l}21.21 \\
(7.08)\end{array}$ & $\begin{array}{c}22.54 \\
(13.77)\end{array}$ & $\begin{array}{c}23.17 \\
(16.97)\end{array}$ & 19.81 & $\begin{array}{l}21.30 \\
(10.10)\end{array}$ & $\begin{array}{c}23.01 \\
(19.90)\end{array}$ & $\begin{array}{c}24.80 \\
(44.69)\end{array}$ \\
\hline $\begin{array}{l}\text { Evapotranspiration } \\
(\mathrm{mm})\end{array}$ & 483.18 & $\begin{array}{l}476.85 \\
(-1.31)\end{array}$ & $\begin{array}{l}463.87 \\
(-4.00)\end{array}$ & $\begin{array}{l}447.11 \\
(-7.46)\end{array}$ & 483.18 & $\begin{array}{c}528.02 \\
(2.01)\end{array}$ & $\begin{array}{l}513.71 \\
(-0.75)\end{array}$ & $\begin{array}{l}500.58 \\
(-3.29)\end{array}$ \\
\hline Evaporation (mm) & 236.50 & $\begin{array}{l}234.94 \\
(-0.66)\end{array}$ & $\begin{array}{l}237.97 \\
(0.62)\end{array}$ & $\begin{array}{l}239.99 \\
(1.48)\end{array}$ & 236.50 & $\begin{array}{r}236.79 \\
(0.12)\end{array}$ & $\begin{array}{l}241.73 \\
(2.21)\end{array}$ & $\begin{array}{l}254.96 \\
(7.81)\end{array}$ \\
\hline $\begin{array}{l}\text { Transpiration } \\
\text { (mm) }\end{array}$ & 281.11 & $\begin{array}{c}291.54 \\
(3.71)\end{array}$ & $\begin{array}{l}285.20 \\
(1.46)\end{array}$ & $\begin{array}{l}274.64 \\
(-2.30)\end{array}$ & 281.11 & $\begin{array}{c}291.22 \\
(3.60)\end{array}$ & $\begin{array}{l}271.98 \\
(-3.25)\end{array}$ & $\begin{array}{c}245.62 \\
(-12.62)\end{array}$ \\
\hline $\begin{array}{l}\text { Surface discharge } \\
(\mathrm{mm})\end{array}$ & 275.45 & $\begin{array}{c}419.1 \\
(11.63)\end{array}$ & $\begin{array}{l}442.83 \\
(17.95)\end{array}$ & $\begin{array}{l}460.10 \\
(22.55)\end{array}$ & 275.45 & $\begin{array}{l}399.24 \\
(6.34)\end{array}$ & $\begin{array}{l}463.61 \\
(23.48)\end{array}$ & $\begin{array}{l}518.04 \\
(37.98)\end{array}$ \\
\hline Percolation (mm) & 208.79 & $\begin{array}{l}202.70 \\
(-2.92) \\
\end{array}$ & $\begin{array}{l}187.93 \\
(-9.99) \\
\end{array}$ & $\begin{array}{c}184.12 \\
(-1182) \\
\end{array}$ & 208.79 & $\begin{array}{l}194.46 \\
(-6.87)\end{array}$ & $\begin{array}{c}181.48 \\
(-13.08)\end{array}$ & $\begin{array}{l}188.95 \\
(-9.50)\end{array}$ \\
\hline $\begin{array}{l}\text { Deep percolation } \\
(\mathrm{mm})\end{array}$ & 18.35 & $\begin{array}{l}17.68 \\
(-3.66)\end{array}$ & $\begin{array}{c}16.58 \\
(-9.67)\end{array}$ & $\begin{array}{c}16.02 \\
(-12.70)\end{array}$ & 18.35 & $\begin{array}{l}17.15 \\
(-6.54)\end{array}$ & $\begin{array}{c}16.17 \\
(-11.86)\end{array}$ & $\begin{array}{c}15.28 \\
(-16.72)\end{array}$ \\
\hline Irrigation (mm) & 616.36 & $\begin{array}{c}618.55 \\
(0.36)\end{array}$ & $\begin{array}{l}627.68 \\
(1.84)\end{array}$ & $\begin{array}{l}633.57 \\
(2.79)\end{array}$ & 616.36 & $\begin{array}{l}625.27 \\
(1.45)\end{array}$ & $\begin{array}{c}636.16 \\
(3.21)\end{array}$ & $\begin{array}{l}632.22 \\
(2.57)\end{array}$ \\
\hline
\end{tabular}


According to Table 6, the precipitation, and maximum and minimum temperature are expected to increase by $8.49 \%, 15.72 \%$, and $7.08 \%$, respectively under RCP 4.5 , while $6.38 \%, 26.73 \%$ and $10.10 \%$ increase under RCP8.5, respectively, as compared to the baseline period during beginning of the century (the 2010s). An increase of $12.44 \%$ in precipitation, $9.15 \%$ in maximum temperature, and $13.77 \%$ in minimum temperature were also projected by the middle of the century (the 2040s) under RCP4.5, compared to the baseline period. However, the most significant increases in rainfall, and maximum and minimum temperature of $13.98 \%, 11.95 \%$, and $19.90 \%$, respectively, were projected for during the middle of the century (the 2040s) under RCP8.5. Precipitation was also expected to increase by $14.47 \%$ and $23.00 \%$ by the end of the century (the 2070s) under RCP4.5 and RCP 8.5 , respectively. The maximum and minimum temperatures were projected to increase by $11.22 \%$ and $18.24 \%$, and $16.97 \%$ and $44.69 \%$ under respective RCP4.5 and RCP8.5 climate scenarios.

Overall, the dominant feature detected was the widespread precipitation, maximum, and minimum temperature increase in the 21st century in the Jeonju station area. This result agreed with the previous study by Li and Kim et al. [47], which reported the gradual increases of 70.9 to $233.8 \mathrm{~mm}$ and 1.7 to $5.7^{\circ} \mathrm{C}$ in annual precipitation and temperature, respectively, for two periods (2019-2059) and (2060-2099) under RCP 4.5 and RCP 8.5 climate change scenarios

\subsection{Future Change in Evapotranspiration, Transpiration, and Evaporation}

The evapotranspiration (ET), transpiration, and evaporation of the cropping period (June to September) over the GCMs were evaluated for the 2010s, 2040s, and 2070s, compared to the historical period (1976-2005) under the RCP4.5 and RCP8.5 scenarios (Figure 7). The projected percentage change in averaged evapotranspiration and transpiration tended to decrease in the future over the experimental areas, compared to the baseline period (historical, 1976-2005), while the evaporation showed a trend of increase.

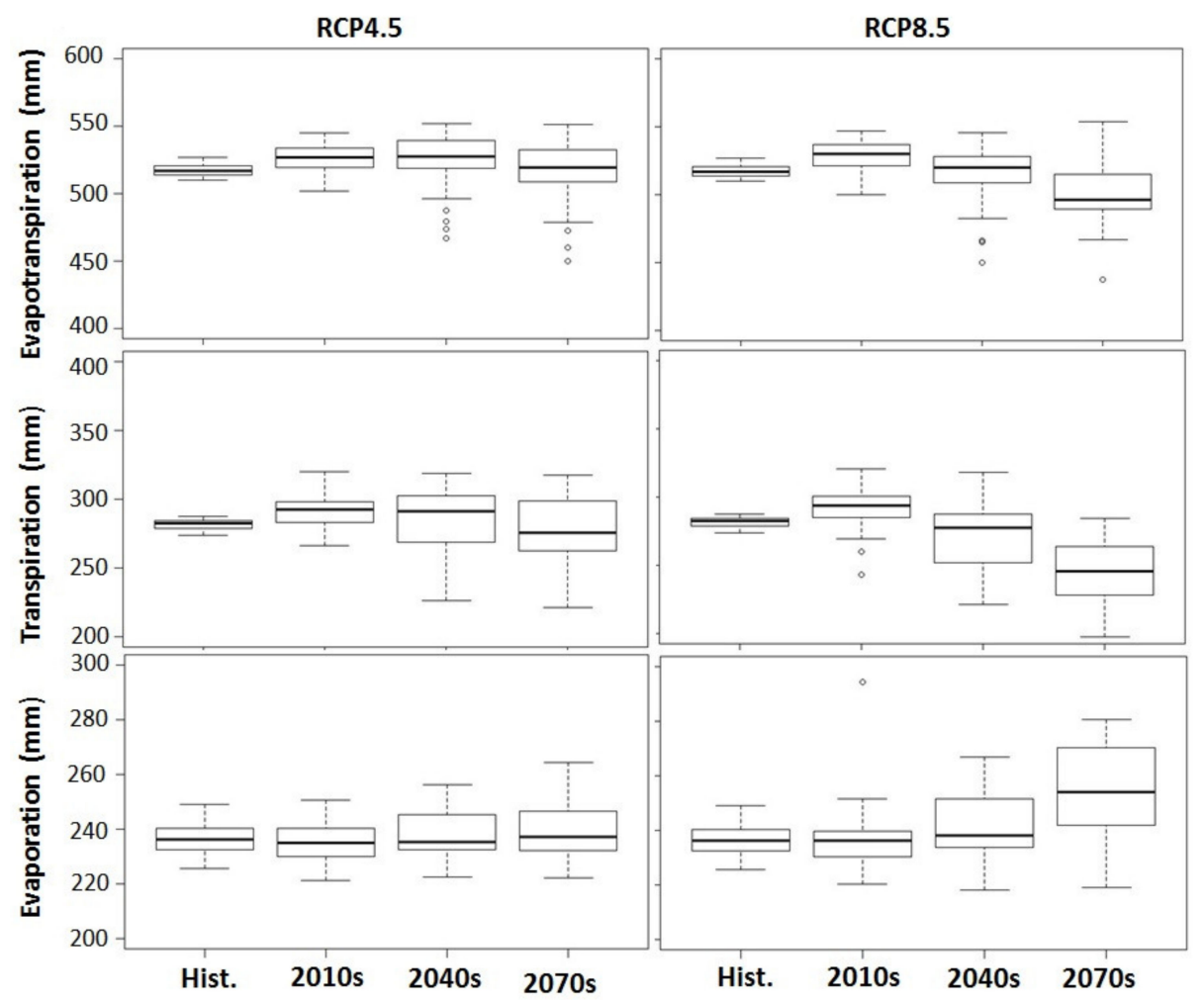

Figure 7. Percentage (\%) change of evapotranspiration, transpiration and evaporation during the cropping period (June-September) in Jeonju metrological station area for the 2010s (2nd column), 2040s (3rd column), 2070s (4rd column) considering RCP4.5 (left side) and (2) RCP 8.5 (right side) scenarios relative to the historical period (1st column) considered as baseline (1976-2005). 
The transpiration amount is expected to increase by $3.71 \%$ under RCP4.5, while a $3.60 \%$ increase under RCP8.5 is shown, as compared to the baseline period during the beginning of the century (the 2010s). According to Table 6, an increase of $1.46 \%$ in transpiration also projected for the middle of the century (the 2040s) under RCP4.5 scenarios, compared to the baseline period, while a 3.25\% decrease was projected under RCP8.5. It was also expected to be decreased by $2.30 \%$ and $12.62 \%$ by the end of the century (the 2070s) under RCP4.5 and RCP8.5, respectively. In the RCP4.5 scenario, a slight decrease in evaporation by $0.66 \%$ during the 2010 s was shown. However, an increase of evaporation by $0.62 \%$ and $1.48 \%$ was found during the 2040 s and 2070 s, respectively. In the RCP 8.5 scenario, the change in evaporation was more pronounced than in the RCP4.5 scenario. The increase of evaporation was likely to increase by $0.12 \%, 2.21 \%$, and $7.81 \%$ compared to the base period during the $2010 \mathrm{~s}, 2040$ s, and 2070s, respectively, under RCP8.5 scenarios. In particular, the evapotranspiration amount was estimated to decrease by $7.46 \%$ in the RCP4.5 scenario and 3.29\% in the RCP 8.5 scenario by the 2070s compared to the baseline. However, only an increased amount was found during the 2010s under RCP8.5, namely, by $2.01 \%$.

Evapotranspiration (ET) is caused by a combination of factors associated with increasing $\mathrm{CO}_{2}$ concentrations, including warmer temperatures and reduced conductivity of bulk canopies. An increase in air temperature allows for the saturation deficit to rise, leading to higher evaporative demand in the air and higher ET levels. Nevertheless, increasing concentrations of $\mathrm{CO}_{2}$ in the atmosphere are likely to lead to some reduction in stomatal conductance, which will minimize transpiration levels for the canopy. Because of the effects of increasing temperature, the stomatal closure under elevated $\mathrm{CO}_{2}$ has a quantitatively greater effect in decreasing transpiration levels than increasing transpiration rates. The ET values reflect the amount of water lost, and must therefore be supplemented by irrigation and/or rainfall.

\subsection{Future Change in Surface Discharge}

The impacts of future climate change on surface discharge were evaluated using the APEX-Paddy model. A total of 29 bias-corrected CMIP5 GCM models outputs of RCP4.5 and RCP8.5 climate scenarios were applied to the surface discharge evaluation, and future projection results were arranged for the baseline period (historical, 1976-2005) and the three periods (the 2010s, 2040s, and 2070s) (Figure 8). The surface discharge generally expected to increase over time in the future under both climate scenarios.
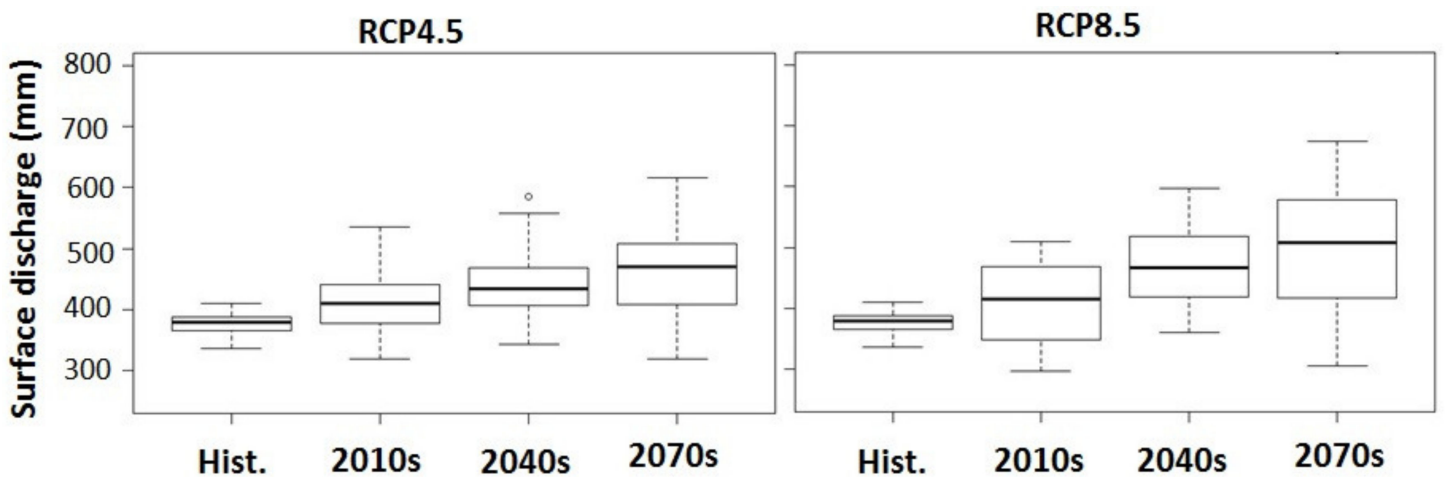

Figure 8. Percentage (\%) change of surface discharge during the cropping period (June-September) in the Jeonju metrological station area for the 2010s (2nd column), 2040s (3rd column), 2070s (4rd column) considering RCP4.5 (left side) and (2) RCP 8.5 (right side) scenarios relative to the historical period (1st column) considered as baseline (1976-2005).

According to Figure 8, an increase in surface discharge is simulated in all projections for different time steps. Surface discharge varied the most from 318.44 to 616.50 and from 304.81 to $829.35 \mathrm{~mm}$ during the 2070s for respective RCP4.5 and RCP8.5 scenarios over the GCMs. Compared to the baseline; the most significant change is expected to increase in the 2070 s by $37.98 \%$ under RCP 8.5 , while the 
lowest increase was found by $6.34 \%$ in 2010 s under RCP8.5 as shown in Table 6 . The increasing rate is comparatively higher in RCP8.5 than RCP4.5 in all-time steps except in the 2010s. It makes sense, as there is a strong positive relationship between surface discharge and precipitation amount.

\subsection{Future Change in Percolation and Deep Percolation}

The impacts of future climate change on percolation and deep percolation were evaluated using the APEX-Paddy model. The future projection results were arranged for the baseline period (historical, 1976-2005) and the three periods (the 2010s, 2040s, and 2070s) under RCP8.5 and RCP4.5 (Figure 9). Overall, the projection shows a decrease in both percolation and deep percolation for all stages compared to the baseline period in both climate scenarios.

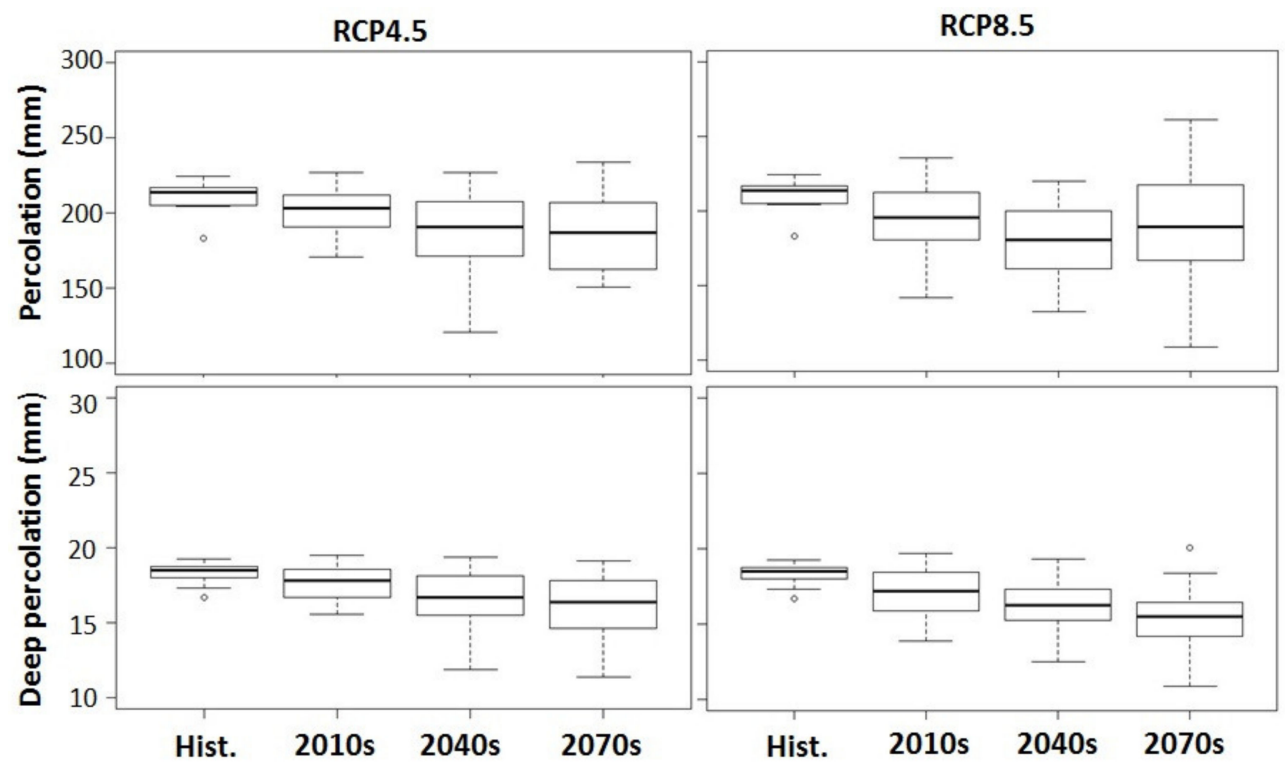

Figure 9. Percentage (\%) change of percolation, and deep percolation during the cropping period (June-September) in the Jeonju metrological station area for the 2010s (2nd column), 2040s (3rd column), 2070s (4rd column) considering RCP4.5 (left side) and (2) RCP 8.5 (right side) scenarios relative to the historical period (1st column) considered as baseline (1976-2005).

The percolation varied the most, with a range of 150.25 to $234.01 \mathrm{~mm}$, and 108.21 to $261.66 \mathrm{~mm}$ during the 2070s for respective RCP4.5 and RCP8.5 scenarios over the GCMs. Compared to the baseline, the most significant change expected is a decrease in the 2040s by $13.08 \%$ under RCP8.5, while the lowest increase found was $2.92 \%$ in 2010 s under RCP4.5. The decreasing rate is comparatively higher in RCP8.5 than RCP4.5 in all stages (Table 6).

Furthermore, the deep percolation varied the most, with a range of 11.33 to $19.11 \mathrm{~mm}$, and 10.83 to $20.07 \mathrm{~mm}$ during the 2070s for respective RCP4.5 and RCP8.5 scenarios over the GCMs. Compared to the baseline, the most significant change expected is a decline under RCP8.5 by $16.72 \%$ in the 2070 s, while the lowest rise was observed under RCP4.5 by $3.66 \%$ in the 2010 s (Table 6 ). The decreasing rate is comparatively higher in RCP8.5 than RCP4.5 in all stages. The relation between rainfall changes and the effect on percolation and deep percolation shows the opposite behavior. However, the highest decrease of percolation was shown for the 2040s under RCP8.5, which is higher than the 2070s (Figure 9). The percolation is not reflected in the precipitation amount compared to the 2040s and 2070s under RCP8.5. It may have happened due to the change in precipitation pattern due to climate change.

\subsection{Future Change in Irrigation}

The impacts of climate change on the irrigation water demand were evaluated using the APEX-Paddy model. A total of 29 bias-corrected CMIP5 GCMs outputs of RCP4.5 and RCP8.5 
climate scenarios were applied to the irrigation water demand evaluation, and future projection results were arranged for the baseline period (historical, 1976-2005) and the three periods (the 2010s, 2040s, and 2070s) (Figure 10). The irrigation water demand was generally expected to increase over time in the future under both climate scenarios. Irrigation water demand varied the most from 543.98 to $687.21 \mathrm{~mm}$ and from 520.37 to $704.60 \mathrm{~mm}$ during the 2070s for respective RCP4.5 and RCP8.5 scenarios over the GCMs.

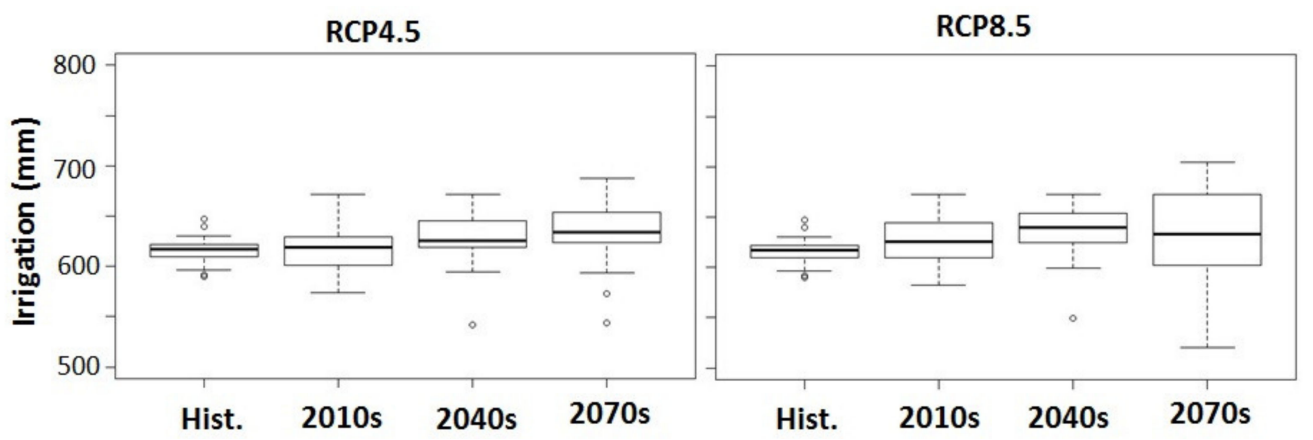

Figure 10. Percentage (\%) change of irrigation during the cropping period (June-September) in the Jeonju metrological station area for the 2010s (2nd column), 2040s (3rd column), 2070s (4rd column) considering RCP4.5 (left side) and (2) RCP 8.5 (right side) scenarios relative to the historical period (1st column) considered as baseline (1976-2005).

Relative to the baseline, the most significant change expected under RCP8.5 is an increase of 3.21\% in the 2040s, whereas the lowest increase is $0.36 \%$ under RCP4.5 in the 2010s (Table 6). The increment of irrigation does not show a significant difference; the rate of increase in the irrigation was found to be greater RCP8.5 than RCP4.5 except in the 2070s. In the 2070s, irrigation water demand is expected to increase by $2.79 \%$, respectively, under RCP4.5, while there is a $2.57 \%$ increase under RCP8.5, as compared to the baseline period.

Although the increment of irrigation does not show a significant difference, it is expected to decrease due to the decreasing trend of evapotranspiration. However, it is not reflected in the current study. It may happen due to the changes in the precipitation pattern as well as effective rainfall due to the effect of climate change. Rainfall was shown to increase overall, while effective rainfall varied according to the ponding depth of the paddy field as it was affected by rainfall intensity or the number of rainy days. However, the APEX-Paddy model is limited in its simulation of effective rainfall.

The results of this study are consistent with Choi [48], where he measured the impacts of climate change on paddy field irrigation water requirements in South Korea using the APEX-Paddy model, which is expected to increase by up to 2.7 per cent in the during 2070 s compared to the base period (1976-2005), but is not significantly increased.

\section{Conclusions}

This study examined the characteristics of the rainfall, temperature, and carbon dioxide responses of the APEX-Paddy model, so as to evaluate the effects of climate change on the water balance components of paddy cultivation. In the study area, the growing season's (June-September) rainfall, and maximum and minimum temperatures for future scenarios were projected to increase by $6.38-23 \%$, 9.15-16.97\% and 7.08-44.69\%, respectively. For the scenarios modeled, the hydrological simulations indicate over-proportional runoff-rainfall and under-proportional percolation and deep percolation rainfall relationships. Overall, the evapotranspiration (ET) amount is estimated to decrease by $7.46 \%$ in the RCP4.5 scenario and 3.29\% in the RCP8.5 by the 2070 s compared to the baseline. An increase in air temperature causes the saturation deficit to rise, leading to higher evaporative demand in the air, resulting in high ET levels. However, increasing concentrations of atmospheric $\mathrm{CO}_{2}$ are likely to contribute to a decrease in stomatal conductance, which will minimize transpiration levels for canopy. 
Due to the effect of rising temperature, the stomatal closure under elevated $\mathrm{CO}_{2}$ has a quantitatively greater effect in reducing transpiration levels than increasing transpiration rate. ET values indicate the amount of water lost, and must therefore be supplemented by irrigation and/or rainfall. However, in the present study, the irrigation water demand was generally likely to increase over time in the future under both climate scenarios. Compared to the baseline, the major change in irrigation water demand is expected to increase in the 2040s by $3.21 \%$ under RCP8.5, while the lowest increase was found to be $0.36 \%$ in 2010 s under RCP4.5. Although the increment of irrigation does not show a significant difference, it is expected to decrease due to the future decreasing trend of evapotranspiration. However, it is not reflected in this study. Despite the fact that the rainfall will be increased in the future, the effective rainfall may vary according to the ponding depth of the paddy field as it will be affected by rainfall intensity or the rainfall days as well as rainfall patterns. According to the previous study by Chung at el. [41], most of the increased rainfall falls after the peak demand period of rice cultivation in the future resulted in increased irrigation demand in South Korea. Therefore, it is most needed to calculate effective rainfall in the modeling approach to justify this study's results. However, the APEX-Paddy model application is limited to effective rainfall measurement.

The APEX-Paddy model is expected to be used as a tool for water management plans considering climate change and for vulnerability assessment of rice productivity. This study has forecast changes in the demands of agricultural water from climate change and has provided an index to quantitatively reflect the water vulnerability of paddy rice. In addition, it has given policy baseline data and adaptive solutions for agricultural water resources. Nonetheless, climate change projections include some degree of uncertainty depending on the downscaling techniques or spatial resolution used $[49,50]$. Therefore, sensitivity analysis may produce different results.

This study refers directly to the Iksan area in South Korea, but indirectly to comparable regions due to the advantages mentioned above in methodological terms. As a follow-up, APEX-Paddy will continue to be used to demonstrate the feasibility of implementing best management practices (BMPs) for sustainable water management in paddy fields at Korea's national scale, and the results will be incorporated into agricultural policy development.

Author Contributions: M.K. contributions as a first author of this article. M.K. designed the research, analyzed the data, and wrote the manuscript; S.H. supervised the study and providing critical evaluations of the manuscript; S.-K.C. provided important intellectual content; J.C., I.S., J.-H.S., H.J., T.J., and S.-H.Y. helped in the preparation of the manuscript and subsequent revisions. All authors have read and agreed to the published version of the manuscript.

Funding: This research was funded by the Research Program for Agricultural Science and Technology Development, National Institute of Agricultural Sciences, Rural Development Administration, Korea, project number PJ01254903.

Acknowledgments: The authors are grateful to Texas A\&M AgriLife Research, USDA Agricultural Research Service, and USDA Natural Resources Conservation Service for providing the modeling software and supports.

Conflicts of Interest: The authors declare no conflict of interest.

\section{References}

1. Inter-Governmental Panel on Climate Change (IPCC). Summary for Policymakers. In Climate Change 2013: The Physical Science Basis; Contribution of Working Group I to the Fifth Assessment Report of IPCC; Cambridge University Press: Cambridge, UK, 2013.

2. Trenberth, K.E. Changes in precipitation with climate change. Clim Res. 2013, 47, 123-138. [CrossRef]

3. Wang, K.; Dickinson, R.E.; Liang, S. Global Atmospheric Evaporative Demand over Land from 1973 to 2008. J. Clim. 2012, 25, 8353-8361. [CrossRef]

4. Xu, C.Y.; Widen, E.; Halldin, S. Modelling hydrological consequences of climate change-progress and challenges. Adv. Atmos. Sci. 2005, 22, 789-797. [CrossRef]

5. Fowler, H.J.; Kilsby, C.G. Using regional climate model data to simulate historical and future river flows in northwest England. Clim. Chang. 2007, 80, 337-367. [CrossRef]

6. Hong, S.Y.; Kanamitsu, M. Dynamical downscaling: Fundamental issues from an NWP point of view and recommendations. Asia Pac. J. Atmos. Sci. 2014, 50, 83-104. [CrossRef] 
7. Kang, S.; Hur, J.; Ahn, J.B. Statistical downscaling methods based on APCC multi-model ensemble for seasonal prediction over South Korea. Int. J. Climatol. 2014, 34, 3801-3810. [CrossRef]

8. Lee, J.W.; Hong, S.Y. Potential for added value to downscaled climate extremes over Korea by increased resolution of a regional climate model. Theor Appl Climatol. 2014, 117, 667-677. [CrossRef]

9. Brigode, P.; Oudin, L.; Perrin, C. Hydrological model parameter instability: A source of additional uncertainty in estimating the hydrological impacts of climate change? J Hydrol. 2013, 476, 410-425. [CrossRef]

10. Lespinas, F.; Ludwig, W.; Heussner, S. Hydrological and climatic uncertainties associated with modeling the impact of climate change on water resources of small Mediterranean coastal rivers. J Hydrol. 2014, 511, 403-422. [CrossRef]

11. Robock, A.; Turco, R.P.; Harwell, M.A.; Ackerman, T.P.; Andressen, R.; Chang, H.S.; Sivakumar, M.V.K. Use of general circulation model output in the creation of climate change scenarios for impact analysis. Clim. Change 1993, 23, 293-335. [CrossRef]

12. Claudia, T.; Reto, K. The use of the multi-model ensemble in probabilistic climate projections. Phil. Trans. $R$. Soc. A. 2007, 365, 2053-2075.

13. Sperber, K.R.; Annamalai, H.; Kang, I.S.; Kitoh, A.; Moise, A.; Turner, A.; Zhou, T. The Asian summer monsoon: An intercomparison of CMIP5 vs. CMIP3 simulations of the late 20th century. Clim. Dyn. 2013, 41, 2711-2744. [CrossRef]

14. Ministry of Construction and Transportation, Republic of Korea (MOCT). Water Vision 2020; MOCT: Seoul, Korea, 2006.

15. McKenney, M.S.; Rosenberg, N.J. Sensitivity of some potential evapotranspiration estimation methods to climate change. Agric. For. Meteorol. 1993, 64, 81-110. [CrossRef]

16. Schlenker, W.; Hanemann, W.M.; Fisher, A.C. Water Availability, Degree Days, and the Potential Impact of Climate Change on Irrigated Agriculture in California. Clim. Change 2007, 81, 19-38. [CrossRef]

17. Jee, Y.K.; Lee, J.H.; Kim, S.D. Climate change impacts on agricultural water in Nakdong-river watershed. J. Korean Soc. Agricul. Eng. 2012, 54, 149-157. (in Korean).

18. Chung, S.-O.; Rodríguez-Díaz, J.A.; Weatherhead, E.K.; Knox, J.W. Climate change impacts on water for irrigating paddy rice in South Korea. Irrig. Drain. 2011, 60, 263-273. [CrossRef]

19. Frederick, K.D.; Major, D.C. Climate Change and Water Resources. Clim. Change 1997, 37, 7-23. [CrossRef]

20. Wigmosta, M.S.; Vail Lance, W.; Lettenmaier, D.P. A distributed hydrology-vegetation model for complex terrain. Water Resour. Res. 1994, 30, 1665-1679. [CrossRef]

21. Holsten, A.; Vetter, T.; Vohland, K. Impact of climate change on soil moisture dynamics in Brandenburg with a focus on nature conservation areas. Ecol. Model. 2009, 220, 2076-2087. [CrossRef]

22. Krysanova, V.; Hattermann, F.; Wechsung, F. Development of the ecohydrological model SWIM for regional impact studies and vulnerability assessment. Hydrol. Process. 2005, 19, 763-783. [CrossRef]

23. Limousin, J.M.; Rambal, S.; Ourcival, J.M. Long-term transpiration change with rainfall decline in a Mediterranean Quercus ilex forest. Global Change Biol. 2009, 15, 2163-2175. [CrossRef]

24. Chin, Y.M.; Park, S.W.; Kim, S.M.; Kang, M.S.; Kang, M.G. Nutrient loads estimation at paddy field using CREAMS-PADDY model. J. Korean Soc. Rural Plann. 2002, 8, 60-68, (In Korean with English Abstract).

25. Chung, S.O.; Kim, H.S.; Kim, J.S. Model development for nutrient loading from paddy rice fields. Agric. Water Manag. 2003, 62, 1-17. [CrossRef]

26. Jeon, J.H.; Yoon, C.G.; Donigian, A.S., Jr.; Jung, K.W. Development of the HSPF-Paddy model to estimate watershed pollutant loads in paddy farming regions. Agricult. Water Manag. 2007, 90, 75-86. [CrossRef]

27. Leipprand, A.; Gerten, D. Global effects of doubled atmospheric $\mathrm{CO}_{2}$ content on evapotranspiration, soil moisture and runoff under potential natural vegetation. Hydrologic. Sci. J. 2006, 51, 171-185. [CrossRef]

28. Choi, S.K.; Kim, M.K.; Jeong, J.; Choi, D.; Hur, S.O. Estimation of Crop Yield and Evapotranspiration in Paddy Rice withe Climate Change using APEX-Paddy Model. J. Korean Soc. Agricul. Eng. 2017a, 59, 27-42, (in Korean with English abstract).

29. Choi, S.K.; Jeong, J.; Cho, J.; Hur, S.O.; Choi, D.; Kim, M.K. Assessing the Climate Change Impacts on Paddy Rice Evapotranspiration Considering Uncertainty. J. Clim. Change Res. 2018, 9, 143-156. [CrossRef]

30. Kim, J.S.; Oh, S.Y.; Oh, K.Y. Nutrient runoff from a Korean rice paddy watershed during multiple storm events in the growing season. J. Hydrol 2005, 327, 128-139. [CrossRef] 
31. Hong, H.C.; Choi, H.C.; Hwang, H.G.; Kim, Y.G.; Moon, H.P.; Kim, H.Y.; Yea, J.D.; Shin, Y.S.; Choi, Y.H.; Cho, Y.C.; et al. A lodging-tolerance and dull rice cultivar 'Baegjinju'. Korean J. Breed Sci. 2012, 44, 51-56, (in Korean with English Abstract).

32. Williams, J.R.; Izaurralde, R.C. The APEX Model.; BRC Report No. 2005-02; Texas Agricultural Experiment Station, Texas Agricultural Extension Service, Texas A\&M University: Temple, TX, USA, 2005.

33. Williams, J.R.; Izaurralde, R.C. The APEX Model. In Watershed Models; Singh, V.P., Frevert, D.K., Eds.; CRC Press, Taylor \& Francis: Boca Raton, FL, USA, 2006.

34. Choi, S.K.; Jeong, J.; Kim, M.K. Simulating the Effects of Agricultural Management on Water Quality Dynamics in Rice Paddies for Sustainable Rice Production-Model Development and Validation. Water 2017b, 9, 869. [CrossRef]

35. Steglich, E.M.; Jeong, J.; Williams, J.R. Agricultural Policy/Environmental eXtender Model.: User's Manual; Version 1501; NRCS and AgriLife Research, Texas A\&M System: Texas, TX, USA, 2016.

36. Hargreaves, G.H.; Samani, Z.A. Reference crop evapotranspiration from temperature. ASAE 1985, 1, 96-99. [CrossRef]

37. Li, Z.; Yang, Y.; Kan, G.; Hong, Y. Study on the Applicability of the Hargreaves Potential Evapotranspiration Estimation Method in CREST Distributed Hydrological Model (Version 3.0) Applications. Water 2018, 10, 1882. [CrossRef]

38. Mockus, V. National Engineering Handbook Section 4, Hydrology; United States Department of Agriculture (USDA), Soil Conservation Service: Washington, DC, USA, 1972.

39. Wang, X.; Jeong, J. APEX-CUTE 4 User Manual; Texas A\&M AgriLife Research, Blackland Research and Extension Center, Texas A\&M University: Temple, TX, USA, 2016.

40. Tolson, B.A.; Shoemaker, C.A. Dynamically dimensioned search algorithm for computationally efficient watershed model calibration. Water Resour. Res. 2007, 43, W01413. [CrossRef]

41. Moriasi, D.N.; Gitau, M.W.; Pai, N.; Daggupati, P. Hydrologic, and water quality models: Performance measures and evaluation criteria. Trans. ASABE 2015, 58, 1763-1785.

42. Mudgal, A.; Baffaut, C.; Anderson, S.H.; Sadler, E.J.; Thompson, A.L. Apex model assessment of variable landscapes on runoff and dissolved herbicides. Trans. ASABE 53 2010, 1047-1058. [CrossRef]

43. Kamruzzaman, M.; Cho, J.; Song, J.H.; Song, I.; Choi, S.K.; Hwang, S. Evaluating the Performance of APEX-PADDY Model using the monitoring data of paddy fields in South Korea. J. Korean Soc. Agricul. Eng. 2019, 62, 1-16.

44. Taylor, K.E.; Stouffer, R.J.; Meeh, G.A. A summary of the CMIP5 experiment design. Available online: https://pcmdi.llnl.gov/mips/cmip5/Taylor_CMIP5_design.pdf (accessed on 24 May 2019).

45. Cho, J.; Cho, W.; Jung, I. RSQM: Statistical Downscaling Toolkit for Climate Change Scenario Using Nonparametric Quantile Mapping. 2018. Available online: Cran.r-project.org/web/packages/rSQM/index.html (accessed on 24 May 2019).

46. Gudmundsson, L.; Bremnes, J.B.; Haugen, J.E.; Engen-Skaugen, T. Technical Note: Downscaling RCM precipitation to the station scale using statistical transformations-A comparison of methods. Hydrol. Earth Syst. Sci. 2012, 16, 3383-3390. [CrossRef]

47. Li, T.; Kim, G. Impacts of Climate Change Scenarios on Non-Point Source Pollution in the Saemangeum Watershed, South Korea. Water 2019, 11, 1982. [CrossRef]

48. Choi, S.K. APEX-Paddy Model Development and Climate Change Impact Assessment for Paddy Rice. Ph.D. Thesis, Seoul National University, South Korea, 2019.

49. Chen, J.; Brissette, F.P.; Leconte, R. Uncertainty of downscaling method in quantifying the impact of climate change on hydrology. J. Hydrol. 2011, 401, 190-202. [CrossRef]

50. Oh, S.G.; Suh, M.S.; Lee, Y.S.; Ahn, J.B.; Cha, D.H.; Lee, D.K.; Hong, S.Y.; Min, S.K.; Park, S.C.; Kang, H.S. Projections of high resolution climate change for South Korea using multiple-regional climate models based on four RCP scenarios. Part 2: Precipitation. Asia-Pac. J. Atmos. Sci. 2016, 52, 171-189. [CrossRef]

(C) 2020 by the authors. Licensee MDPI, Basel, Switzerland. This article is an open access article distributed under the terms and conditions of the Creative Commons Attribution (CC BY) license (http://creativecommons.org/licenses/by/4.0/). 